\title{
Applications of nano-indentation methods to estimate nanoscale mechanical properties of shale reservoir rocks
}

\author{
Kouqi Liu \\ University of North Dakota, kouqi.liu@UND.edu \\ Mehdi Ostadhassan \\ University of North Dakota, mehdi.ostadhassan@UND.edu \\ Bailey Bubach \\ University of North Dakota, bailey.bubach@UND.edu
}

\section{How does access to this work benefit you? Let us know!}

Follow this and additional works at: https://commons.und.edu/pe-fac

\section{Recommended Citation}

Kouqi Liu, Mehdi Ostadhassan, and Bailey Bubach. "Applications of nano-indentation methods to estimate nanoscale mechanical properties of shale reservoir rocks" (2016). Petroleum Engineering Faculty Publications. 1.

https://commons.und.edu/pe-fac/1

This Article is brought to you for free and open access by the Department of Petroleum Engineering at UND Scholarly Commons. It has been accepted for inclusion in Petroleum Engineering Faculty Publications by an authorized administrator of UND Scholarly Commons. For more information, please contact und.commons@library.und.edu. 


\title{
Applications of nano-indentation methods to estimate nanoscale mechanical properties of reservoir rocks
}

\author{
Kouqi Liu*, Mehdi Ostadhassan, Bailey Bubach \\ Department of petroleum engineering, University of North Dakota, Grand Forks 58203, ND, USA \\ *Corresponding author, email address: Kouqi.liu@my.und.edu
}

\begin{abstract}
In order to study the mechanical properties of shale samples from Bakken Formation, nanoindentation method, an imaging technique borrowed from other engineering disciplines, was used. Different types of nanoindentation curves were analyzed and the applicability of the nanoindentation theories to study mechanical properties of shale samples at nanoscale was demonstrated. Elastic modulus and Hardness of different samples were calculated, compared and related to their mineral compositions and microstructures which are detected by 2D XRD and FESEM methods, respectively. Results showed that samples with more clay minerals (mainly composed of illite) and larger pore structures have less Young's modulus. In addition, based on the energy analysis method, the fracture toughness at nanoscale was estimated and its relationships with Young's modulus was quantified. It was observed that fracture toughness increases linearly with Young's modulus. This paper presents the results and major findings of this study.
\end{abstract}

Keywords: Nanoindentation, Bakken shale formation, Mechanical properties, Fracture toughness, Nanoscale

\section{Introduction}

As the first commercially successful application in 1950, hydraulic fracturing has been performed worldwide in oil and gas wells (King, 2012). Especially in the past decade, hydraulic fracturing has been an essential technique to enhance the production of the hydrocarbon from unconventional reservoirs such as shale gas, tight gas, shale oil and coal methane. Fracturing increases not only the production but also the total reserves that can be produced (Montgomery and Smith, 2010). Rock's elastic and mechanical properties such as elastic modulus, fracture toughness and Poisson's ratio are critical design parameters in hydraulic fracturing. Elastic modulus can influence the stability of fractures while fracture toughness - a generic term for analyzing material resistance to extension of a crack - can affect the geometry of the fractures (Thiercelin et al., 1989). Characterizing and quantifying these parameters has already been studied by many researchers in the past (Ghamgosar et al., 2015; Park et al., 2004; Senseny and Pfeifle, 1984; Thiercelin, 1987; Too et al., 2015; Zoback, 1978). However, due to the mineralogical variability, mechanically and chemically unstable properties of the shale formations, it is very expensive and sometimes even impossible to obtain suitable size samples for standard mechanical testing. Nanoindentation, which only requires a small sample volume, is a technique to detect the local mechanical properties such as Young's modulus and hardness of the materials. This method has been widely used in material science research such as films, biological tissues and other cement-based materials (Naderi et al., 2016; Tanguy et al., 2016; Xiao et al., 2015). In recent years, researchers began to use this method in studying the mechanical properties of shale formations (Kumar et al., 2012; Mason et al., 2014; Shukla et al., 2013), however, they limited their studies only in measuring Young's modulus and hardness. In this paper, we report the results of using nanoindentation to study Bakken Formation samples from the Williston Basin, which is an unconventional reservoir. Estimation of mechanical properties such as Young's modulus, hardness and fracture toughness of the Bakken Formation demonstrates the applicability of the nanoindentation technique in studying shale formations geomechanical properties. 


\section{Theory and Background}

\subsection{Nanoindentation curve}

Nanoindentation is a technique whereby an indenter tip is used to contact the test sample surface under a certain mode and the penetration depth along with the related applied load are recorded (Hu and $\mathrm{Li}, 2015$ ).

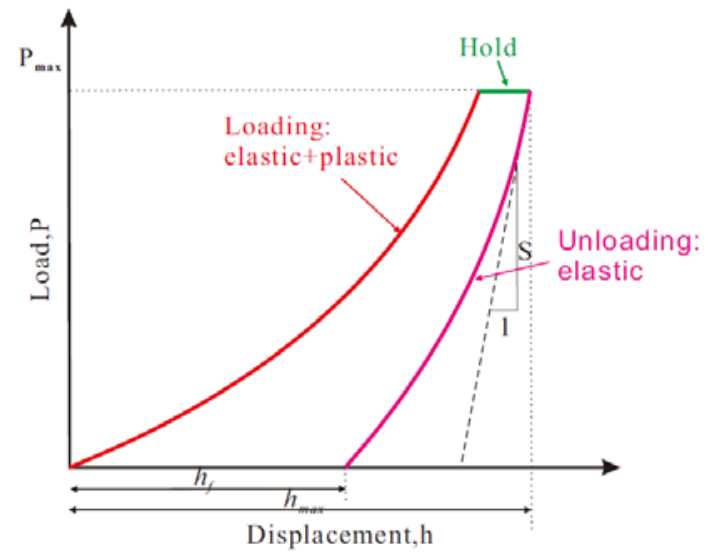

Fig. 1. Schematic illustration of indentation loaddisplacement curve (Hu and $\mathrm{Li}, 2015)$.

Fig. 1 shows the typical indentation curve which consists of three stages of loading, holding and unloading. In the loading stage, the applied load increases as the penetration depth increase. This stage can be regarded as the combination of elastic and plastic deformation, whereas during the unloading stage we can assume that only elastic deformation can be recovered, and this is used to calculate the mechanical properties.

\subsection{Young's modulus and hardness}

In order to estimate Young's modulus and hardness values, several parameters derived from Fig. 1 was analyzed. For instance, contact stiffness $S$, defined as $S=\frac{d P}{d h} /_{h_{\max }}$, which quantifies the slope of the upper portion of the unloading part $\left(h_{\max }\right)$ is one that can provide us with valuable information regarding the mechanical response of the material. In order to eliminate the influence of the bluntness of the indenter on the test results, energy-based analysis was used to calculate the initial contact stiffness (Kaushal K. Jha and Arvind, 2012):

$$
S=0.75 *\left(2 v_{E}-1\right) \frac{P_{\max }}{h_{\max }},
$$

Where $v_{E}$ is called elastic energy ratios which can be defined as the ratio of the absolute work and the elastic work (Fig.2):

$$
v_{E}=\frac{U_{s}}{U_{e}}
$$

Where $U_{s}$ is the absolute work from nanoindentation determined by the area $O A h_{L} O$ whereas $U_{i r}$ is the irreversible energy work determined from the area $O A B h_{\max }$ and $U_{e}$ can be calculated from the area $h_{f} B h_{\max } h_{f}$.

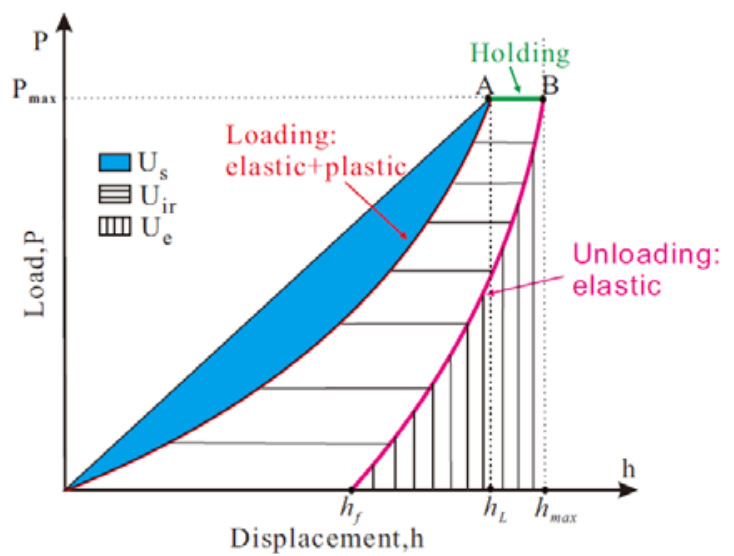

Fig.2. Schematic illustration of the energy analysis for calculation purposes(Kaushal K. Jha and Arvind, 2012).

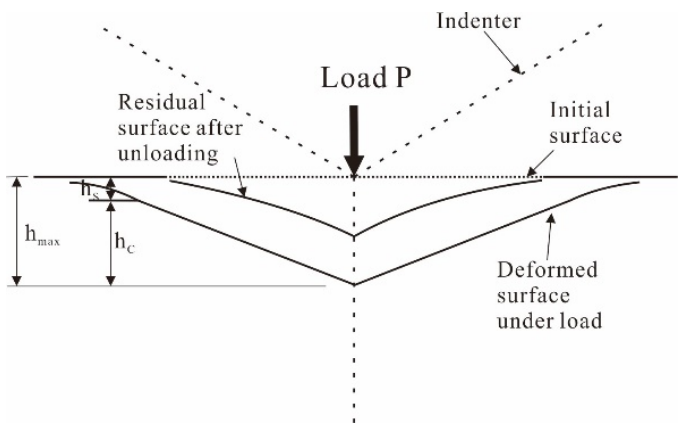

Fig.3. Schematic illustration of the unloading process (Oliver and Pharr, 1992). 
Fig.3 illustrates the unloading process during a typical nanoindentation test, from which it is concluded that

$$
h_{\max }=h_{s}+h_{c} \text {, }
$$

Where $h_{s}$ is the vertical surface deflection at the perimeter of the contact and $h_{c}$ is the contact depth. $h_{s}$ and $h_{c}$ can be derived using the following equation separately( $\mathrm{Hu}$ and $\mathrm{Li}, 2015$; Oliver and Pharr, 1992):

$$
\begin{aligned}
& h_{s}=\varepsilon \frac{P_{\max }}{S} \varepsilon=0.75 \\
& h_{c}=\frac{2\left(v_{E}-1\right)}{\left(2 v_{E}-1\right)} h_{\max }
\end{aligned}
$$

Once initial contact stiffness and contact depth were derived, the reduced Young's modulus can be calculated as (Oliver and Pharr, 1992):

$$
\begin{aligned}
& E_{r}=\frac{\sqrt{\pi} S}{2 \sqrt{A_{c}}}, \\
& \text { Where } \quad A_{c}=24.5 h_{c}^{2} .
\end{aligned}
$$

Finally, the Young's modulus and hardness parameters can be obtained as:

$$
\begin{aligned}
& \frac{1}{E_{r}}=\frac{1-v^{2}}{E}+\frac{1-v_{i}^{2}}{E_{i}} \\
& H=\frac{P_{\max }}{A} /_{h_{\max }}
\end{aligned}
$$

\subsection{Toughness measurement using nanoindentation}

There is a significant growth in the number of researchers who are using nanoindentation methods to study fracture toughness for its accurate and repeatable measurement (Kruzic et al., 2009; Scholz et al., 2004; Sebastiani et al., 2015; Wang et al., 2015), whereas using nanoindentation method to study the fracture toughness of rocks is very scarce to date. In this paper, we acquired nanoindentation technique to study the fracture toughness of shale samples from the Bakken Formation. Due to the inhomogeneous nature of the samples and the difficulty in measuring the crack length during the nanoindentation process, we applied energy analysis method in this study.
The theoretical concept behind the energy analysis method is that the irreversible energy ( $U_{i r}$ ) can be defined as the difference of the total energy $\left(U_{t}\right)$ and the elastic energy $\left(U_{e}\right)$ (Cheng et al., 2002). Then fracture energy ( $\left.U_{\text {crack }}\right)$ can be described using the following equation:

$$
U_{\text {crack }}=U_{i r}-U_{p p}
$$

In this equation $U_{p p}$ is the energy cost due to the pure plasticity which can be calculated using the following mathematical relationship:

$$
\frac{U_{p p}}{U_{t}}=1-\left[\frac{1-3\left(\frac{h_{f}}{h_{\max }}\right)^{2}+2\left(\frac{h_{f}}{h_{\max }}\right)^{3}}{1-\left(\frac{h_{f}}{h_{m}}\right)^{2}}\right]
$$

Therefore the critical energy release rate $G_{c}$ can then be determined as

$$
G_{c}=\frac{\partial U_{\text {crack }}}{\partial A}=\frac{U_{\text {crack }}}{A_{m}},
$$

Where $A_{m}$ is the maximum crack area. For Berkovich indenter, the area can be calculated as $A_{\max }=24.5 h_{\max }^{2}$.

Finally, the fracture stress intensity factor $K_{c}$ can be computed as:

$$
K_{c}=\sqrt{G_{c} E_{r}} \text {. }
$$

\section{Geological Setting and Experiments}

\subsection{Geological setting}

All the samples that are tested are retrieved from the wells drilled through the Bakken Formation in the State of North Dakota, USA. The Bakken Formation is located in the Williston Basin in Montana, North Dakota, and southern Saskatchewan (shown in Fig. 4(a)), has become one of the largest shale plays in the world. In this paper, we analyzed samples from the Well CHARLIE SORENSON 17-8 3TFH. The target Bakken Formation of this well consists of three members: Upper, Middle and Lower Bakken. In this well, the upper Bakken is composed of distinctive black, blocky, carbonaceous shale with an instant milky cut. Then as ROP decreased 
with the increasing drilling depth, the samples changed from the black Upper Bakken Shale to silty Dolomite, indicating the appearance of Middle Bakken Formation. For this well, the Middle Bakken Formation has light gray, off white dolomitic siltstone, finely crystalline, with fair intercrystalline porosity. And for the lower Bakken Formation, samples were collected as the ROP increased again. Samples of the Lower Bakken were typical shale, brownish black in color, fissile, gritty, with bright fluorescence and streaming bright yellow cut. Fig.4 (b) shows the stratigraphic column and the facies distributions of Bakken Formation. Overall, Upper and Lower Bakken is composed of shale with an abundance of clay minerals whereas the Middle Member varies in lithology and consists of interbedded siltstones and sandstones with lesser amounts of clay minerals (Pitman et al., 2001).

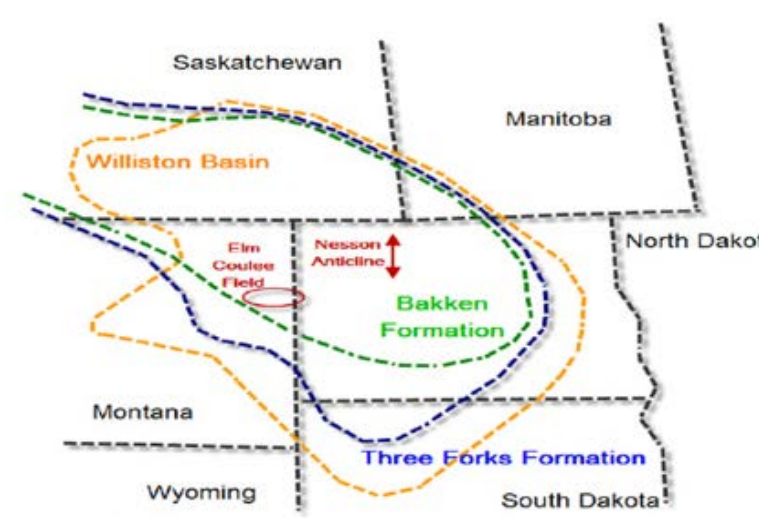

(a)

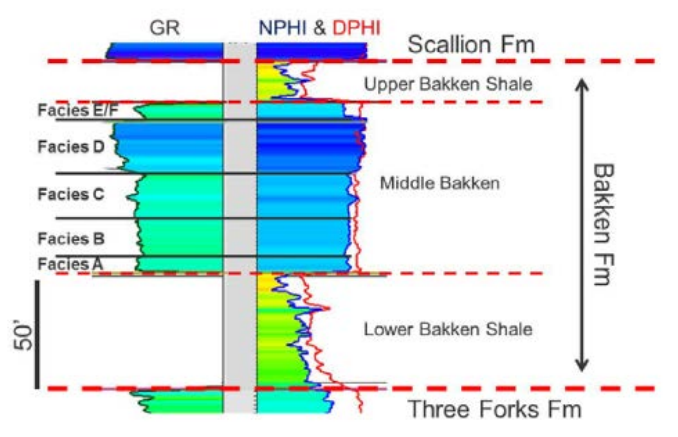

(b)

Fig.4. Schematic of the area and the well we studied in this paper ((a) is the map of Williston and (b) shows the stratigraphic column of Bakken Formation (Li et al., 2015)

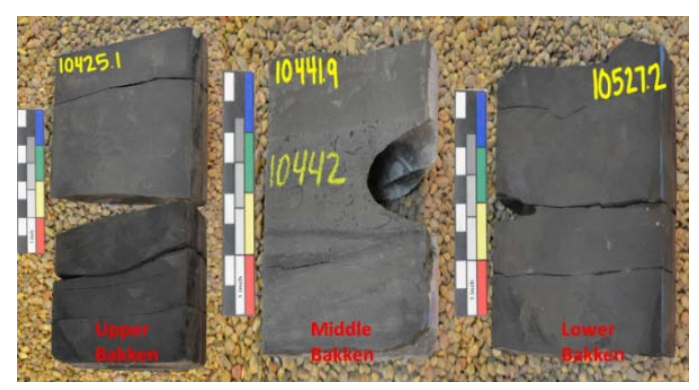

(a) Raw core samples

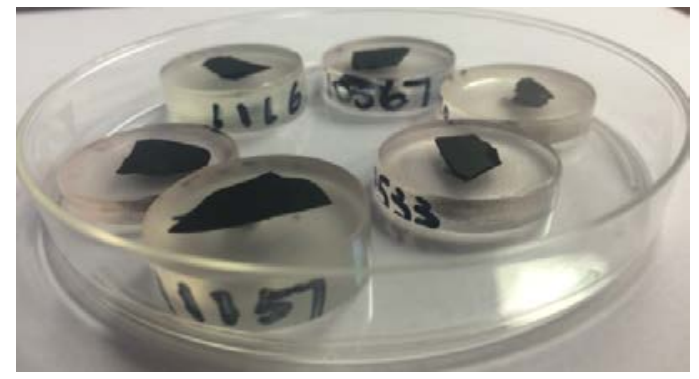

(b) Prepared samples for tests

Fig. 5. Shale samples used in this study

\subsection{Experiments}

To get the most accurate results sample, preparation plays a crucial role. The surface of the smoothness of the sample specimens is very crucial for the accuracy of the results. Based on the combination of log and core photo image analysis, we collected the rock fragments from the original cores extracted from the Bakken Formation available at the North Dakota Core Library. The samples were broken into small pieces and then put in the resin liquid until the resin becomes solid under vacuum conditions. Sand papers of different grit sizes from 600 to 1200 was used to polish the sample surface followed by the different grain size of diamond polishers of 5, 3 and 1 microns. Fig. 5(a) shows the raw samples and Fig. 5(b) represents the prepared samples ready for the tests.

MTS Nanoindenter XP with Berkovich-type indenter (see Fig. 6) was used to test the samples. Indentation experiments were conducted at room temperature and ambient pressure. The instrument operates in a displacement-controlled 
mode with a loading rate of $20 \mathrm{~nm} / \mathrm{s}$. Scores of data were collected as the indenter approaches and retracts from the test point. Then data analysis was carried to calculate the mechanical properties of the sample.

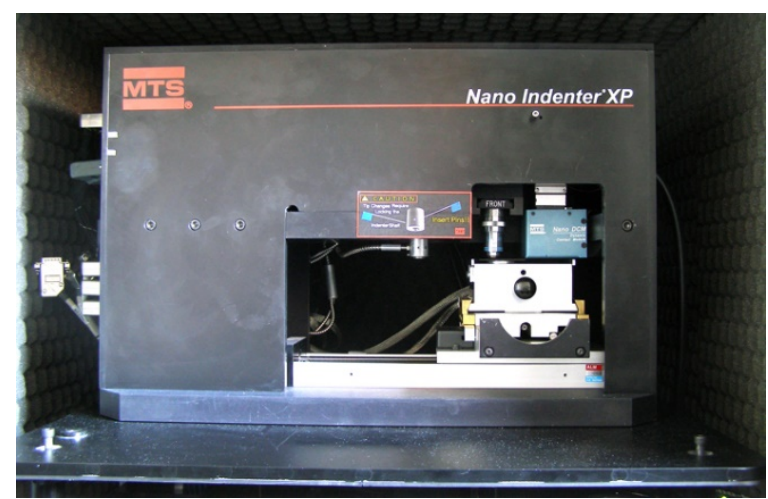

Fig. 6. MTS Nano-indenter (Agilent Company) used in this study

\section{Results and Discussions}

\subsection{Nano-indentation curves analysis}

Fig.7 depicts some typical nanoindentation curves obtained from the tested samples.

All the curves in Fig. 7 show the elastic-plastic deformation during the loading process. Fig.7 (a) illustrates the typical indentation curve without any abnormal phenomenon. From Fig. 7 (b), it is evident that the loading curve shows a normal pattern, however, the unloading curve follows an elbow pattern. The pressure beneath the indenter is very high and always increases as the indentation depth increases. Once the hydrostatic pressure is larger than the critical point, phase transformation occurs (Tabor, 1978). The gradual change of the unloading curve is the result of the material expansion during the slow transformation to the amorphous phase, which contributes to the indenter uplift (Domnich et al., 2000). Fig.7 (c) shows the "pop in" phenomena in the loading curve. This is interpreted due to the cracks forming during the nanoindentation process. When the indenter contacts the material, the work by the indenter will change the elastic energy of the material once the elastic energy increases to a critical value at some point in the contact field, plastic deformation occurs with the increasing load. For the elastic-plastic materials such as rocks, their elastic energy is almost invariant within the localized plastic deformation zones. However, rocks which are just exterior to this zone and in a state of incipient plastic deformation have less elastic energy and the elastic energy decreases significantly as the distance from the contact zone increases. The large energy difference in different zones can lead to the formation of the cracks (Cook and Pharr, 1990; Lawn et al., 1980; Oyen and Cook, 2009). Fig.7 (d) shows combinations of "pop in" and "elbow” phenomena.

The parameters of curve fitting to the loading and unloading stages of Fig. 7 (a), (b), (c) and (d) are calculated respectively and reported in Table 1. The results explain that the loading and unloading curves fit the power law functions listed below very well:

$$
\begin{aligned}
& P=K h^{n} \text { (loading), } \\
& P=\alpha\left(h-h_{f}\right)^{m} \text { (unloading) }
\end{aligned}
$$

Where $P$ and $h$ are the loading force and displacement, respectively. $h_{f}$ is the residual displacement. $K, n, \alpha$ and $m$ are constants which can be calculated based on the experiments.

This is a similar behavior observed in other materials(Lawn et al., 1980), proving that the theory of nanoindentation may be used for the calculation of rock mechanical properties.

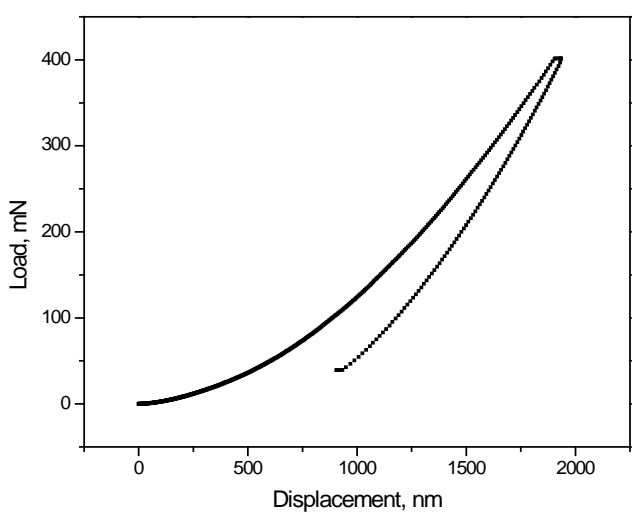

(a) Normal 


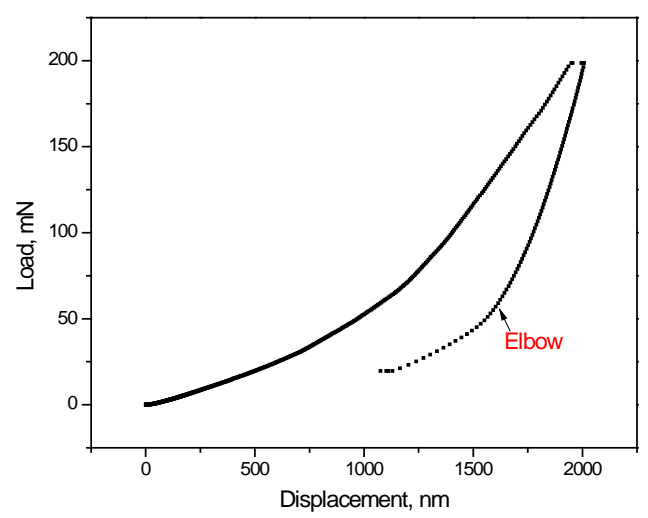

(b) Elbow

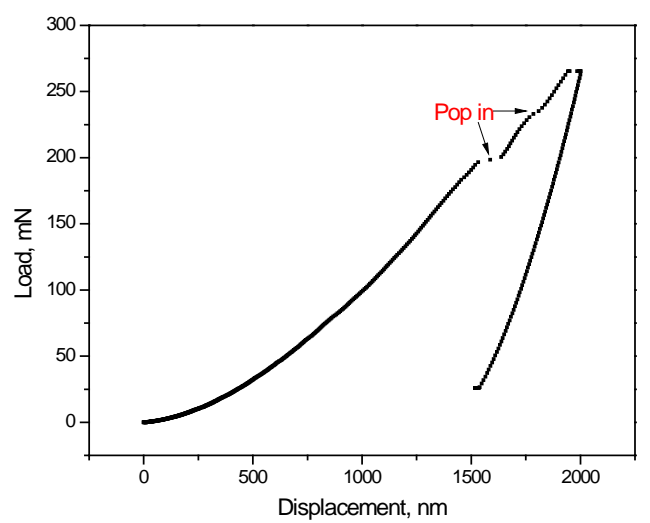

(c) Pop in

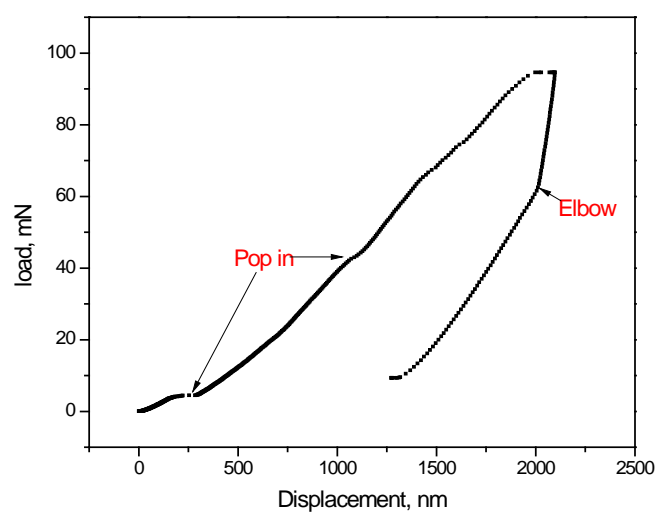

(d) Pop in and Elbow

Fig. 7. Typical nanoindentation curves identified during testing the Bakken Shale samples.
Table 1 Curve fitting analysis of the loading and unloading processes, respectively

\begin{tabular}{|c|c|c|c|c|}
\hline & & $K$ & $n$ & $R^{2}$ \\
\hline \multirow{4}{*}{$\begin{array}{c}\text { Loading } \\
\text { process }\end{array}$} & $\mathrm{a}$ & 0.00048 & 1.80591 & 0.99992 \\
\cline { 2 - 5 } & $\mathrm{b}$ & 0.00013 & 1.87968 & 0.99586 \\
\cline { 2 - 5 } & $\mathrm{c}$ & 0.00265 & 1.52325 & 0.99848 \\
\hline & $\mathrm{d}$ & 0.02687 & 1.15039 & 0.96086 \\
\hline & & $\alpha$ & $m$ & $R^{2}$ \\
\hline \multirow{4}{*}{$\begin{array}{c}\text { Unloading } \\
\text { process }\end{array}$} & $\mathrm{a}$ & 0.07906 & 1.22777 & 0.99450 \\
\cline { 2 - 5 } & $\mathrm{b}$ & 0.0049 & 1.50995 & 0.99044 \\
\cline { 2 - 5 } & $\mathrm{c}$ & 0.14466 & 1.21886 & 0.99238 \\
\hline & $\mathrm{d}$ & 0.00597 & 1.62741 & 0.98771 \\
\hline
\end{tabular}

\subsection{Elastic modulus and hardness}

Young's modulus and hardness of the samples were derived and their values were plotted versus the penetration depth as shown in Fig.8.

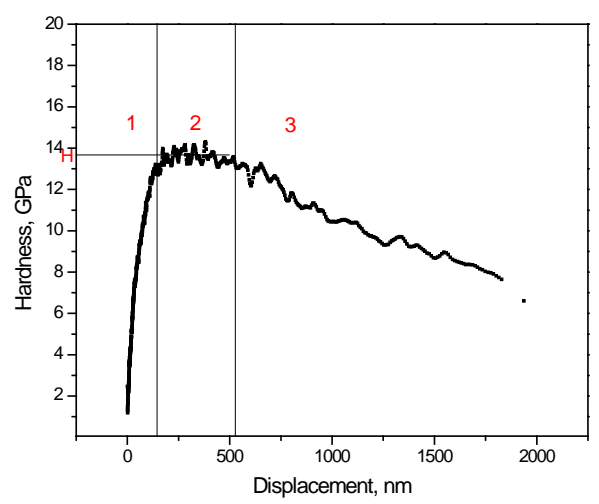

(a) Hardness value

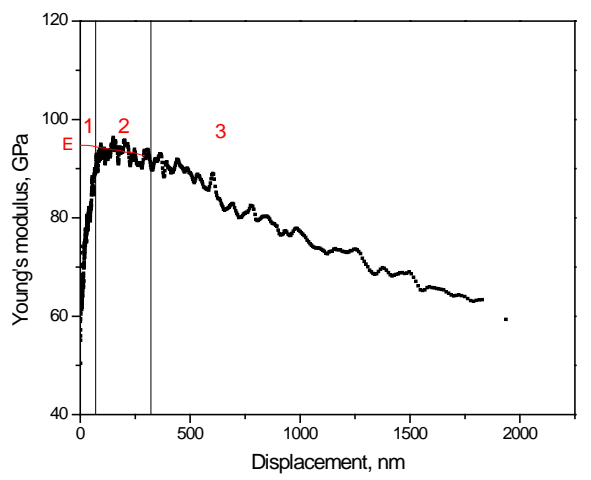

(b) Young's modulus

Fig. 8. Changes of elastic modulus and Hardness versus penetration depth. Both plots show three 
distinguished stages: 1. Initial rising; 2. Plateau; 3.falling off.

Fig. 8 represents the results of a sample for calculating Young's modulus. From this figure, it is concluded that both plots adhere three distinguished stages. During the initial stage, we can assume that the contact is elastic, which means that the values of this stage are the mean values and less than the real mechanical value of the materials. At larger penetration depth, the influence of the substrate on the test values will become more pronounced as is visible from the third stage in the figure, so the hardness value extracted from the plateau stage will be considered as the real hardness value of the sample. For the Young's modulus we use the extrapolation technique (see Fig. 8 (b)). We extended the plot from the second stage to the sample surface (i.e. when displacement equals to 0 ), and where the vertical axis intercept the graph, Young's modulus of the samples is read (FischerCripps, 2006). Following this procedure, for this test point in this sample, its hardness value is obtained to be $13.8 \mathrm{GPa}$ and Young's modulus equal to $95 \mathrm{GPa}$.

Fig.9 shows the elastic modulus and hardness values of the four samples we tested. Sample 1 is from Upper Bakken Formation while sample 2, 3 and sample 4 are from Middle Bakken Formation. The data shows that sample 4 has the highest elastic modulus while sample 3 has the lowest values. More research about the properties of the four samples can be seen in the following section.

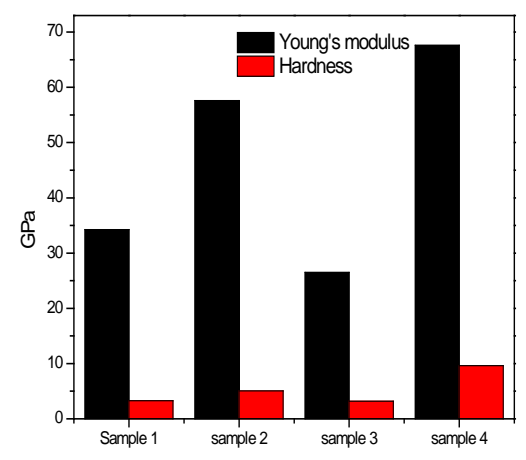

Fig. 9. Elastic properties of different samples.

\subsection{Young's modulus, hardness, mineral compositions and microstructures}

In order to study the relationship between the elastic properties, mineral compositions and microstructures, the four samples with quite different elastic properties derived from nanoindentation test were analyzed by XRD, FESEM

\subsubsection{Mineral compositions}

X-Ray Diffraction (XRD) was performed on the flat surface of the samples using Bruker D8 Discover 2D apparatus. For the rock such as shale, having preferred orientation, the percent crystallinity measured with the conventional diffractometer is not consistent. While the sample orientation has no effect on the full circle integrated diffraction profile from a 2D frame, 2D XRD system can measure percent crystallinity more accurately with consistent results(He, 2003).

Fig. 10 presents the images of 3 frames of the 2D XRD scanning for Sample 1. Combining the three frames and the relevant signals for 25-115 degree scan angle produces Fig. 11. Quantitative measurement of the mineral composition can be obtained by analyzing the signal peaks. The results showed this particular sample contained $51.3 \%$ clay minerals (mainly illite) and $31.9 \%$ quartz.

Following a similar procedure, we derived the mineralogical compositions for the rest of the samples (see Table 2).

Table 2 Composition analysis by XRD

\begin{tabular}{|c|c|c|c|c|}
\hline & Sample 1 & Sample 2 & Sample 3 & Sample 4 \\
\hline Quartz & 31.9 & 35.8 & 37.9 & 49.4 \\
\hline Calcite & 0 & 2.5 & 2.6 & 1.7 \\
\hline Dolomite & 12 & 0.1 & 0.3 & 2 \\
\hline Ankerite & 0 & 4 & 6.3 & 3.4 \\
\hline Pyrite & 0 & 3.6 & 5 & 4.8 \\
\hline K-feldspar & 4.7 & 11.2 & 8.7 & 9.8 \\
\hline Albite & 0 & 7.6 & 5.1 & 3.7 \\
\hline $\begin{array}{c}\text { clay } \\
\text { minerals }\end{array}$ & 51.3 & 35.2 & 34 & 25.2 \\
\hline
\end{tabular}


Results show that the two major minerals components of the samples are quartz and clay minerals (mainly composed of illite). Due to the small percentage of other minerals, so in this paper, we neglect their influence on the mechanical properties. Results show that sample 1 has the most clay minerals (51.3\%) and the least amount of quartz (31.3\%) whereas sample 4 has the least clay minerals (25.2\%) with the highest amount of quartz content (49.4\%). Sample 2 and sample 3 has similar mineral compositions (Sample 2 has 35.8\% quartz and 35.2\% clay minerals while sample 3 has $37.3 \%$ quartz and $34 \%$ clay minerals). These results will be crossvalidated by the SEM analysis of the samples presented in the following subsection.

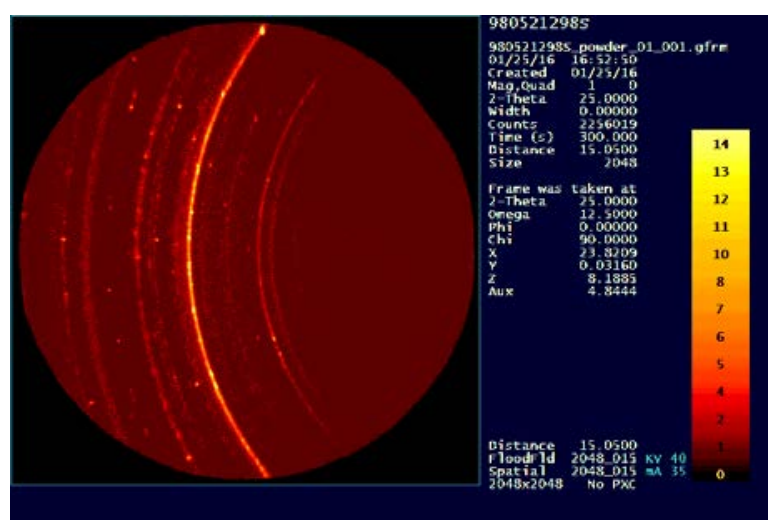

(a)

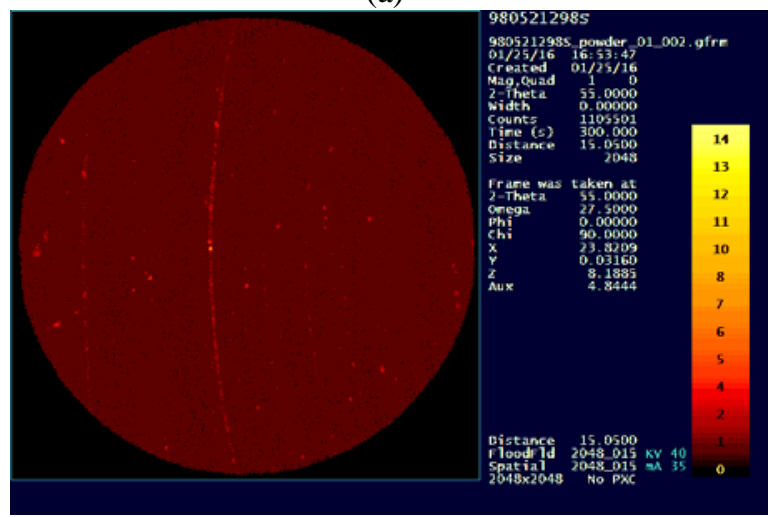

(b)

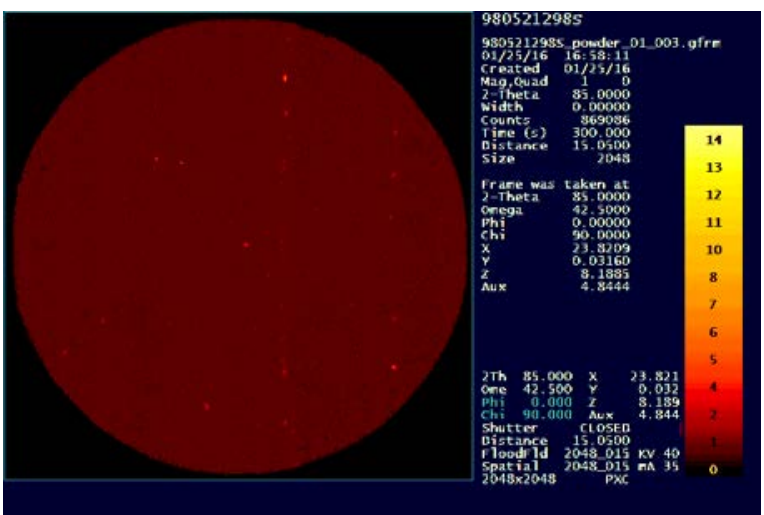

(c)

Fig. 10. Image of 3 Frames of 2D XRD scanning for angles of (a) of $25-55^{\circ}$, (b) $55-85^{\circ}$ and (c) $85-115^{\circ}$ representing one sample.

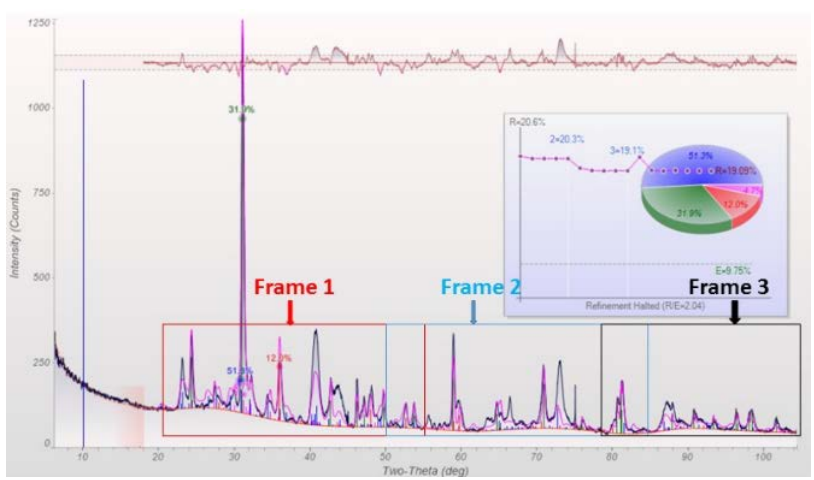

Fig.11. XRD signal of one sample obtained by combining the three frames from Fig. 10.

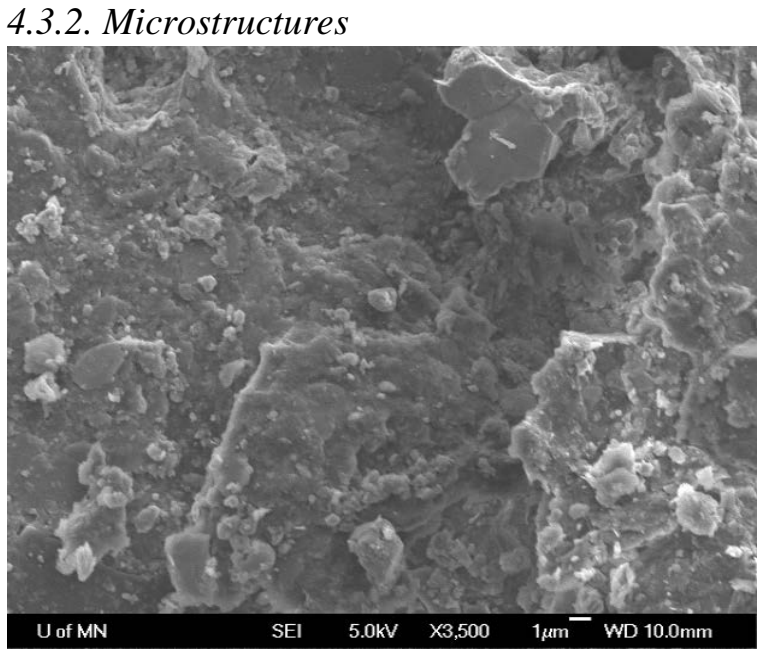

(a) Sample 1 


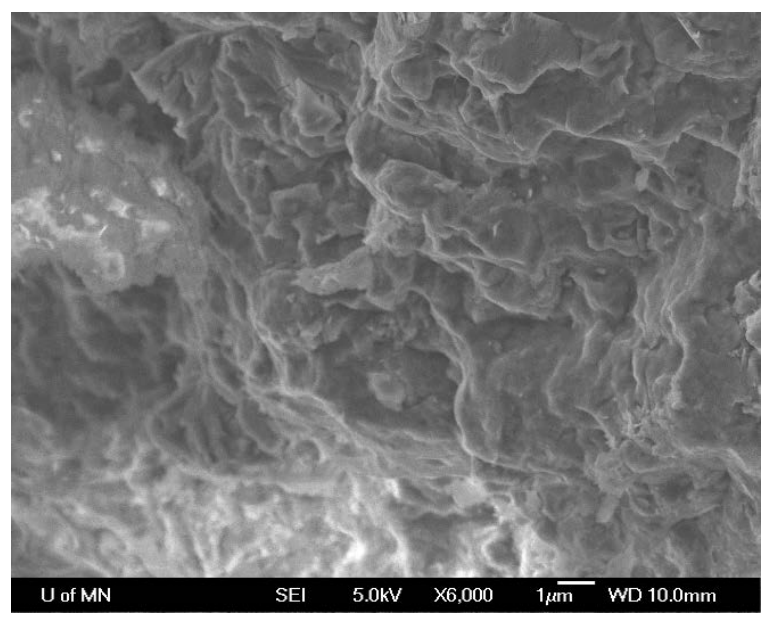

(b) Sample 2

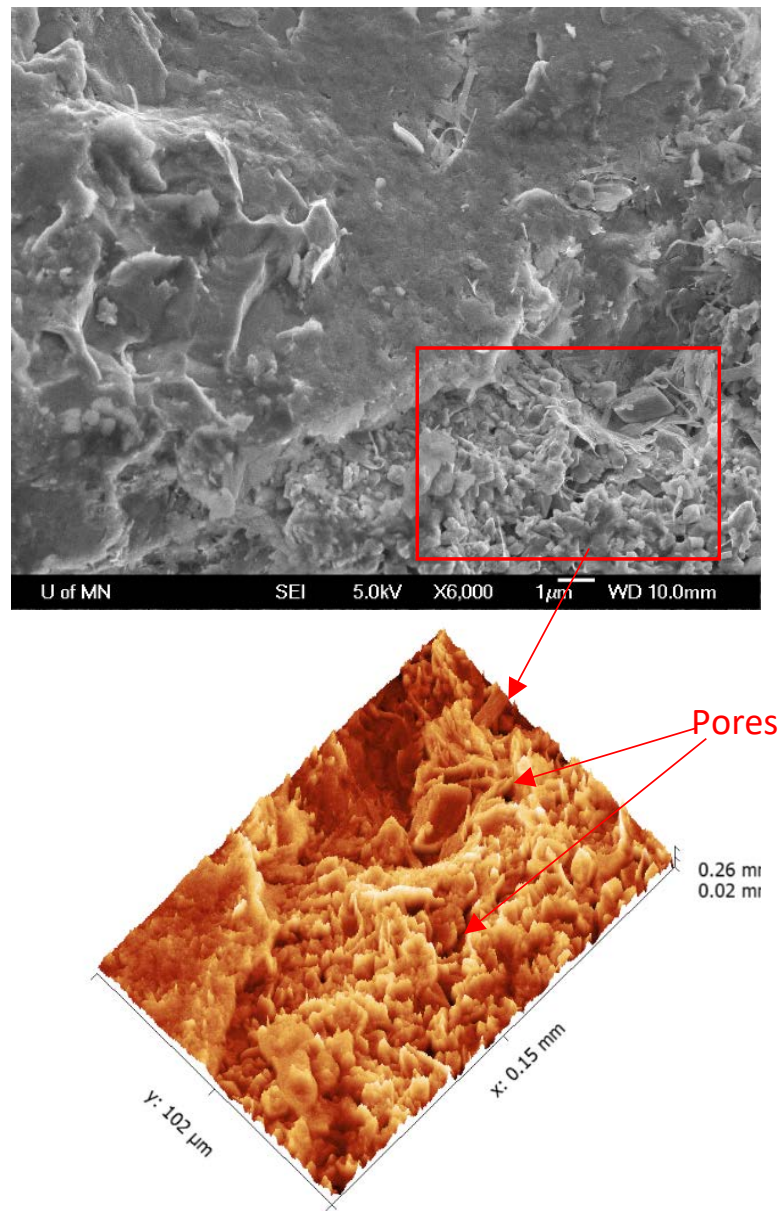

(c) Sample 3

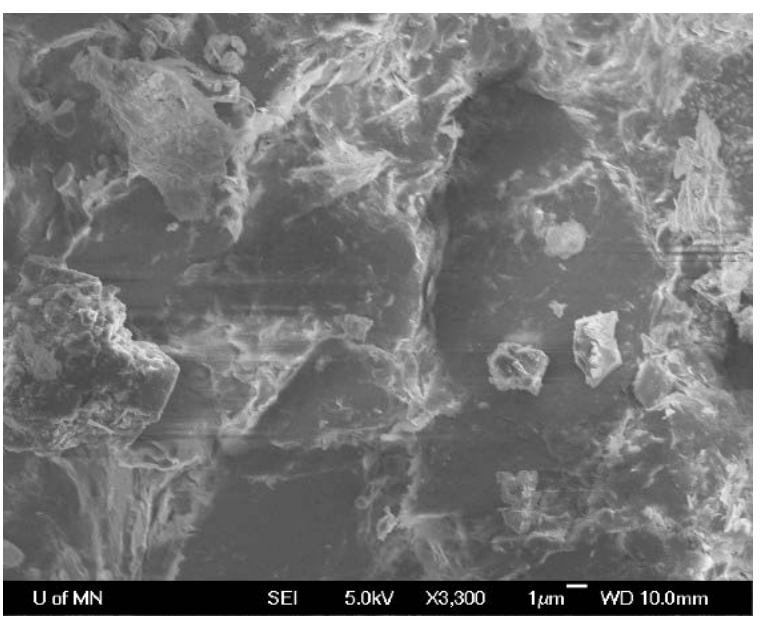

(d) Sample 4

Fig. 12. SEM images of few shale samples from different members of the Bakken Formation.

Field Emission Gun Scanning Electron Microscope JEOL 6500 apparatus (JEOL Company) was used to study the microstructures of the four samples. The results are shown in Fig.12. From this figure, it is observed that samples 1, 2 and 4 have, in order, the highest to the least clay minerals which are in agreement with the XRD analysis results presented earlier. The results also represent that sample 3 has more pores and fractures than the rest.

Comparing the values of Young's modulus and hardness for four different samples which were presented in Fig. 9 with the SEM and XRD data, it's concluded that sample 4 that has the highest Young's modulus and hardness values, and sample 3 with the lowest values exhibit more pore structures and fewer clay minerals respectively.

Packing density which can neatly summarize the porosity and mineralogy information can be used to explain this phenomenon which were defined as below:

$\eta=1-\frac{\varphi}{1-f_{\text {inc }}}$

Where, $\eta$ is the clay packing density, $\varphi$ is the porosity, \%; and $f_{i n c}$ is the clay volume fraction. As the porosity or the clay content increase, the $h$ value will decrease, resulting in the decrease in the Young's modulus and hardness value (Bobko and Ulm, 2008).

Compared with Sample 3, Sample 1 with much higher clay content (17.3\% more) and less lower porosity (2.5\% less) shows higher mechanical 
parameters: Young's modulus and hardness, demonstrating that the impact of the porosity on the mechanical parameters is higher than the clay content which is consistent with multivariate linear regression analysis by Kumar et al. (2012).

\subsection{Fracture toughness test}

Based on the energy analysis method, 20 nanoindentation tests were performed on four different samples from three members of the Bakken Formation.

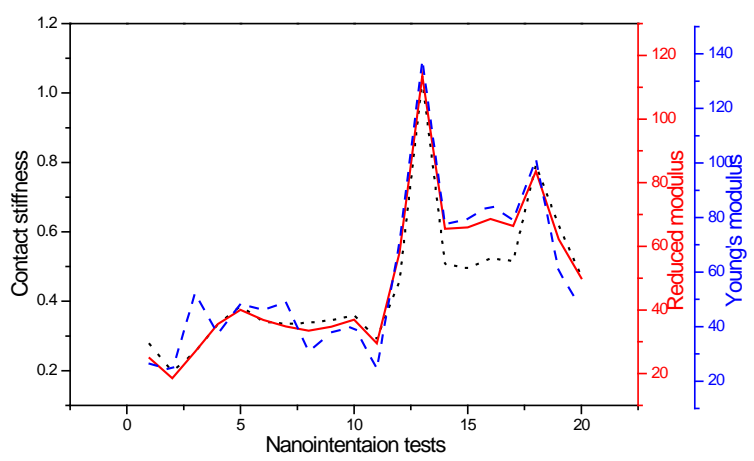

(a)

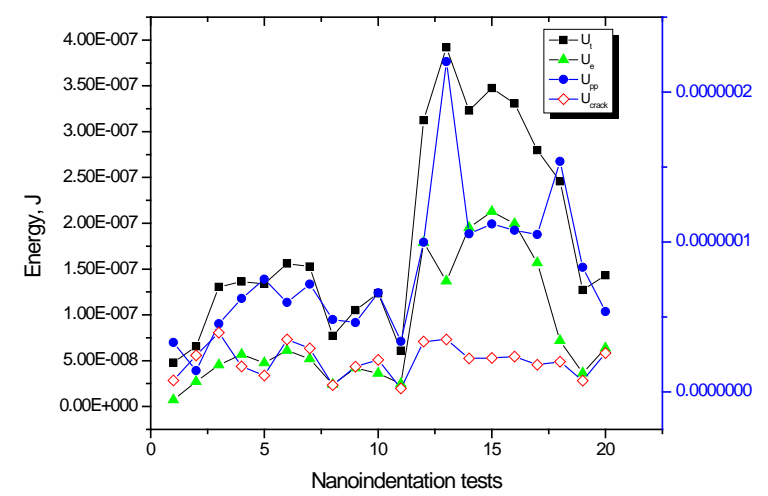

(b)

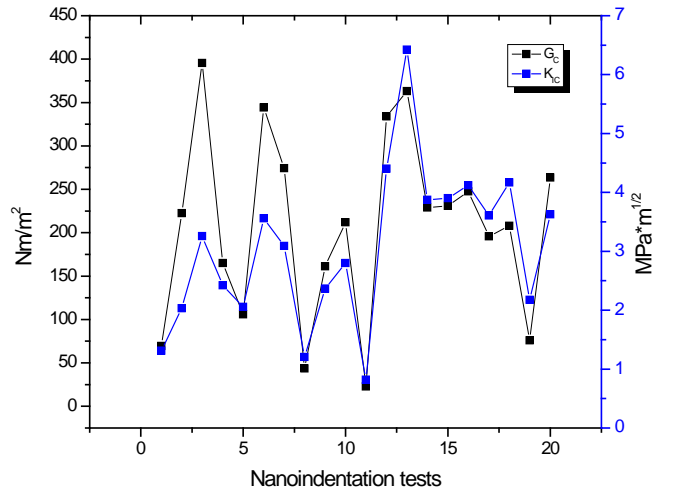

(c)

Fig.13. Energy analysis results from nanoindentation. (a) contact stiffness, reduced modulus and Young's modulus; (b) total energy, plastic energy, elastic energy and crack energy; (c) energy release rate and fracture intensity factor.

Fig.13 (a) depicts the results of the contact stiffness, reduced modulus and Young's modulus. From this figure, it is seen that the higher contact stiffness, the higher the Young's modulus is. This is because the contact stiffness is the value of the slope of the nanoindentation curve at $h_{\max }$. Elastic energy increases as the $S$ increases. So Young's modulus which can reflect the elastic properties of rocks also increases as shown in Fig. 14. Fig. 13 (b) presents the energy distribution corresponding to each nanoindentation test. Fig. 13 (c) depicts the results of the energy release rate and fracture intensity factor of the nanoindentation tests, showing the fracture toughness increases and the energy release rate increases.

The average value of $K_{\text {IC }}$ from Fig. 13(c) for the samples from the Bakken in nanoscale is around 3.06 MPa $\sqrt{m}$. Plotting the Young's modulus versus the toughness values for the samples, a linear relationship is developed at the nanoscale as shown in Fig.15. The following equation allows us to estimate the fracture toughness from Young's modulus at nanoscale:

$$
K_{\text {IC }}=0.7288+0.04048 E
$$

From literature and database, the values of fracture toughness of Bakken formation rocks are rarely to be found while the information of elastic modulus is abundant and easily to be derived. 
Equation 15 gives us a potential estimation of the fracture toughness of Bakken Formation without doing many experiments, saving a lot of time and making more profits.

In this paper, all the mechanical properties such as Young's modulus, Hardness and fracture toughness were calculated under the ambient temperature and pressure which can be a little different from the value of the rocks under the real reservoir conditions. Under the reservoir conditions, the pore structures will change and rocks become more plastic due to the high temperature and high pressure. Also in this paper, we only studied the mechanical properties of the rock sample in nanoscale, which is not suitable to estimate the rocks in large scale directly due to the heterogeneous properties of the rock. In the near future, we will use project nanoindentation and phase characterization method to upscale the mechanical properties of the rocks from nanoscale to a large scale and then we will compare the results from true triaxial test and logs to confirm the validity of this method, however, at this stage, these results provide a good insight in order to understand some nanoscale behavior of these samples, showing the great potential of the application of this method to study rock mechanical properties.

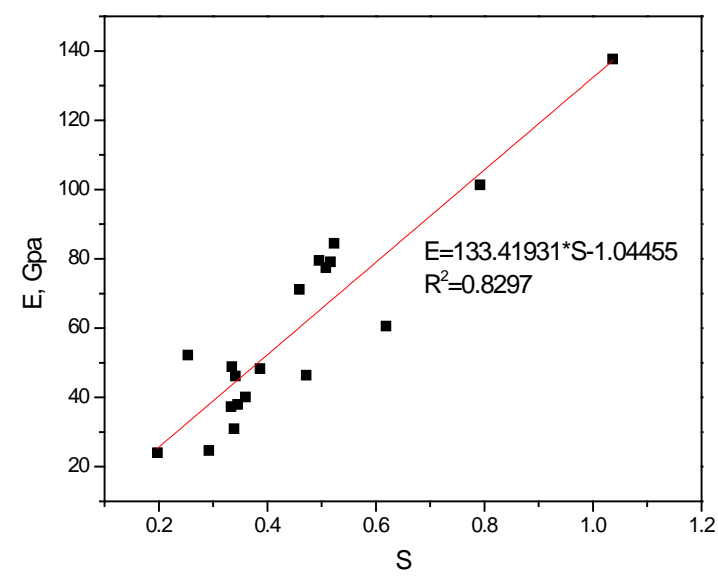

Fig.14. Relationships between contact stiffness and Young's modulus

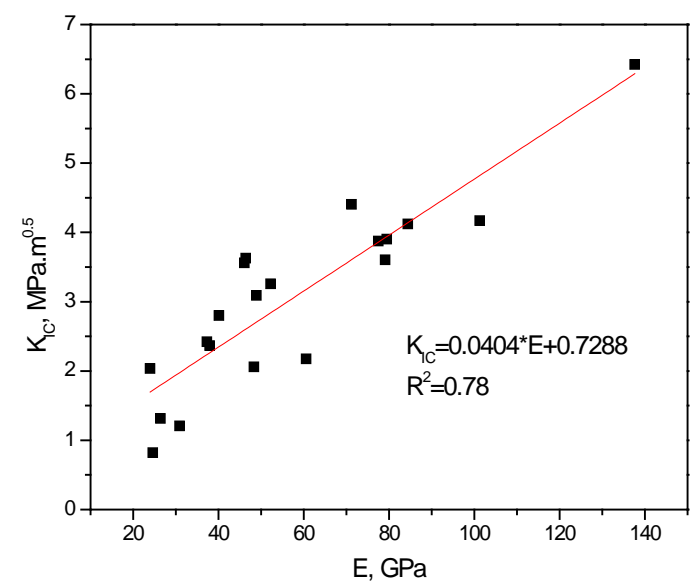

Fig.15. Relationships between Young's modulus and fracture toughness

\section{Conclusions}

In this study, we applied the nanoindentation method to study the mechanical properties of shale samples from Bakken Formation. The analysis of the nanoindentation indicated some abnormal phenomenon such as pop in and elbow. The results of this study showed that the theory of nanoindentation can be applied for studying the mechanical properties of rocks at nano-scale. Young's modulus and hardness values were calculated and compared with their mineral compositions and microstructures. The results suggested that the more clay minerals and pore microstructures present in the samples, the less the elastic Young's modulus and hardness values will be. Based on the energy analysis, fracture toughness of different samples at nanoscale was calculated and compared and the relationship with Young's modulus is developed. The results stated that toughness of the samples tested in this study increases linearly with the Young's modulus. The results of this study provide a great potential application of nanoindentation method in analyzing the rock mechanical properties and predicting fracture properties required in a successful hydraulic fracturing operation in unconventional shale plays (shale gas and shale oil formation). Future work is focused to upscale the mechanical properties in nanoscale to macro and reservoir scale. 


\section{Nomenclature}

$h_{\max } \quad$ Maximum displacement, $\mathrm{nm}$

$P_{\max } \quad$ Maximum indentation load, $m N$

$S \quad$ Contact stiffness

$v_{E} \quad$ Elastic energy ratio

$h_{s} \quad$ Vertical surface deflection, $\mathrm{nm}$

$h_{c} \quad$ Contact depth, $n m$

$h_{f} \quad$ Residual displacement, $\mathrm{nm}$

$E_{r} \quad$ Reduced modulus, $\mathrm{GPa}$

$U_{t} \quad$ Total energy, $J$

$U_{i r} \quad$ Irreversible energy, $J$

$U_{p p} \quad$ Energy cost by plastic deformation, $J$

$U_{e} \quad$ Energy cost by elastic deformation, $J$

$U_{\text {crack }} \quad$ Energy cost by cracks, $J$

$G_{c} \quad$ Energy release rate, $\mathrm{Nm} / \mathrm{m}^{2}$

$K_{\text {IC }} \quad$ Fracture stress intensity factor, $\operatorname{MPa} \sqrt{m}$

\section{Acknowledgement}

The authors would like to thank Characterization Facility Laboratory at the University of Minnesota, (UMN) for allowing us to use their equipment and appreciate the support from China Scholarship Council (CSC). Thank you for the reviewers comments to improve my paper quality.

\section{References}

Cheng, Y.-T., Li, Z. and Cheng, C.-M., 2002. Scaling relationships for indentation measurements. Philosophical Magazine A, 82(10): 1821-1829.

Cook, R.F. and Pharr, G.M., 1990. Direct Observation and Analysis of Indentation Cracking in Glasses and Ceramics. Journal of the American Ceramic Society, 73(4): 787-817.

Domnich, V., Gogotsi, Y. and Dub, S., 2000. Effect of phase transformations on the shape of the unloading curve in the nanoindentation of silicon. Applied Physics Letters, 76(16): 2214-2216.

Fischer-Cripps, A.C., 2006. Critical review of analysis and interpretation of nanoindentation test data. Surface and Coatings Technology, 200(14-15): 4153-4165.

Ghamgosar, M., Williams, D.J. and Erarslan, N., 2015. Effect of Anisotropy on Fracture Toughness and Fracturing of Rocks. American Rock Mechanics Association.

He, B.B., 2003. Introduction to two-dimensional X-ray diffraction. Powder Diffraction, 18(02): 71-85.

$\mathrm{Hu}, \mathrm{C}$. and $\mathrm{Li}, \mathrm{Z}$., 2015. A review on the mechanical properties of cement-based materials measured by nanoindentation. Construction and Building Materials, 90: 80-90.

Kaushal K. Jha, N.S.D.L. and Arvind, A., 2012. Energy-Based Analysis of Nanoindentation Curves for Cementitious Materials. Materials Journal, 109(1).

King, G.E., 2012. Hydraulic Fracturing 101: What Every Representative, Environmentalist, Regulator, Reporter, Investor, University Researcher, Neighbor and Engineer Should Know About Estimating Frac Risk and Improving Frac Performance in Unconventional Gas and Oil Wells. Society of Petroleum Engineers.

Kruzic, J.J., Kim, D.K., Koester, K.J. and Ritchie, R.O., 2009. Indentation techniques for evaluating the fracture toughness of biomaterials and hard tissues. Journal of the Mechanical Behavior of Biomedical Materials, 2(4): 384-395.

Kumar, V., Curtis, M.E., Gupta, N., Sondergeld, C.H. and Rai, C.S., 2012. Estimation of 
Elastic Properties of Organic Matter in Woodford Shale Through Nanoindentation Measurements. Society of Petroleum Engineers.

Lawn, B.R., Evans, A.G. and Marshall, D.B., 1980. Elastic/Plastic Indentation Damage in Ceramics: The Median/Radial Crack System. Journal of the American Ceramic Society, 63(9-10): 574-581.

Mason, J., Carloni, J., Zehnder, A., Baker, S.P. and Jordan, T., 2014. Dependence of Micro-Mechanical Properties on Lithofacies: Indentation Experiments on Marcellus Shale. Society of Petroleum Engineers.

Montgomery, C.T. and Smith, M.B., 2010. Hydraulic Fracturing: History Of An Enduring Technology.

Naderi, S. et al., 2016. Modeling of porosity in hydroxyapatite for finite element simulation of nanoindentation test. Ceramics International, 42(6): 75437550.

Oliver, W.C. and Pharr, G.M., 1992. An improved technique for determining hardness and elastic modulus using load and displacement sensing indentation experiments. Journal of Materials Research, 7(06): 1564-1583.

Oyen, M.L. and Cook, R.F., 2009. A practical guide for analysis of nanoindentation data. Journal of the Mechanical Behavior of Biomedical Materials, 2(4): 396-407.

Park, N., Holder, J. and Olson, J.E., 2004. Discrete Element Modeling Of Fracture Toughness Tests In Weakly Cemented Sandstone. American Rock Mechanics Association.

Pitman, J.K., Price, L.C. and LeFever, J.A., 2001. Diagenesis and fracture development in the Bakken Formation, Williston Basin; implications for reservoir quality in the middle member. 1653.

Scholz, T., Schneider, G.A., Muñoz-Saldaña, J. and Swain, M.V., 2004. Fracture toughness from submicron derived indentation cracks. Applied Physics Letters, 84(16): 3055-3057.
Sebastiani, M., Johanns, K.E., Herbert, E.G. and Pharr, G.M., 2015. Measurement of fracture toughness by nanoindentation methods: Recent advances and future challenges. Current Opinion in Solid State and Materials Science, 19(6): 324333.

Senseny, P.E. and Pfeifle, T.W., 1984. Fracture Toughness Of Sandstones And Shales. American Rock Mechanics Association.

Shukla, P., Kumar, V., Curtis, M., Sondergeld, C.H. and Rai, C.S., 2013. Nanoindentation Studies on Shales. American Rock Mechanics Association.

Tabor, D., 1978. Phase transitions and indentation hardness of $\mathrm{Ge}$ and diamond. Nature, 273(5661): 406-406.

Tanguy, M., Bourmaud, A. and Baley, C., 2016. Plant cell walls to reinforce composite materials: Relationship between nanoindentation and tensile modulus. Materials Letters, 167: 161-164.

Thiercelin, M., 1987. Fracture Toughness Under Confining Pressure Using The Modified Ting Test. American Rock Mechanics Association.

Thiercelin, M., Jeffrey, R.G. and Naceur, K.B., 1989. Influence of Fracture Toughness on the Geometry of Hydraulic Fractures.

Too, J.L. et al., 2015. An Experimental Method to Determine the Fracture Toughness of Brittle and Heterogeneous Material by Hydraulic Fracturing. Society of Petroleum Engineers.

Wang, X. et al., 2015. High damage tolerance of electrochemically lithiated silicon. Nat Commun, 6.

Xiao, G., Yang, X., Yuan, G., Li, Z. and Shu, X., 2015. Mechanical properties of intermetallic compounds at the Sn3.0Ag-0.5Cu/Cu joint interface using nanoindentation. Materials \& Design, 88: 520-527.

Zoback, M.D., 1978. A Simple Hydraulic Fracturing Technique For Determining Fracture Toughness. American Rock Mechanics Association. 